\title{
ALTERIDADE, ETNOGRAFIA VIRTUAL E EDUCAÇÃO: APRENDENDO E ENSINANDO COM O OUTRO
}

\author{
ALTERITY, VIRTUAL ETHNOGRAPHY AND EDUCATION: LEARNING AND \\ TEACHING WITH THE OTHER
}

\author{
COUTO JUNIOR, Dilton Ribeiro \\ junnior@yahoo.com.br \\ Universidade do Estado do Rio de Janeiro
}

\begin{abstract}
RESUMO Este texto tem como objetivo promover uma reflexão sobre a abordagem teórico-metodológica da etnografia virtual (ou netnografia) nas investigações em ambientes virtuais, reconhecendo a importância da alteridade, de modo que pesquisador e sujeitos aprendam juntos. A fundamentação teórico-metodológica apoiou-se nas contribuições da etnografia virtual e no diálogo com autores dos campos da comunicação e educação. Assim, foram trilhados os caminhos necessários para interagir com noventa e oito jovens, dentre eles professores recém-formados, com os saberes compartilhados na interface Facebook. As conclusões da pesquisa apontam para a relevância da referida interface para propiciar que as diferentes vozes dos internautas sejam ouvidas e interpeladas, criando vínculos mais estreitos entre todos os envolvidos nos processos de aprender e ensinar, e abrindo novas possibilidades para que o diálogo online seja potencializado. Isso proporcionou repensar a formação de professores diante das práticas pedagógicas nas interfaces digitais, considerando as dinâmicas da interação e da colaboração, próprias da cultura digital.
\end{abstract}

PALAVRAS-CHAVE: Alteridade. Etnografia Virtual. Educação.

ABSTRACT This text has the objective to promote a reflection about the theoreticalmethodological approach of the virtual ethnography (or netnography) in virtual environment investigations, recognizing the importance of the alterity, so that the researcher and subjects learn together. The theoretical-methodological background is based on the contribution of the virtual ethnography and in the dialogue with authors of the communication and education fields. Therefore, I traversed the necessary paths to interact with ninety-eight youths, among them newly qualified teachers, with the knowledge shared on the Facebook interface. The conclusions of the research aim the relevance of the referred interface to provide that the different voices of the internet users are heard and interpellated, creating narrower bonds between everyone involved in the learning and teaching processes, and opening new possibilities as the online dialogue is intensified. This provided the rethink the 
formation of teachers faced with pedagogical practices in the digital interfaces, considering the interactive and collaborative dynamics, proper of the cyberculture.

KEYWORDS: Alterity. Virtual Ethnography. Education.

\section{PARTINDO DO “POR QUE” E NÃO DO “POIS É”....}

Marinho (2006, p. 20), discutindo sobre os usos das Tecnologias da Informação e Comunicação na educação, propõe:

Penso - e sempre digo isso a meus alunos e alunas - que, para melhorar a escola e a educação, devemos fazer uma pedagogia da incerteza. É o que chamo de pedagogia do 'por quê?', ao contrário da pedagogia do 'pois é', da educação das certezas e dos saberes pré-fixados.

Ensejar a prática do diálogo e da alteridade nos processos de ensinoaprendizagem talvez seja hoje um dos desafios a serem enfrentados para que possamos pensar uma educação para o século XXI. Ao mesmo tempo em que este se constitui, a meu ver, como um dos principais desafios, é também um caminho que poderia ser trilhado para propiciar que, juntos, professores e estudantes estejam engajados e comprometidos com a produção coletiva do conhecimento.

Este estudo parte do pressuposto de que na busca pelo caminho teóricometodológico nos ambientes virtuais, o "por quê?" se apresenta como uma alternativa mais interessante do que o "pois é".

Numa perspectiva alteritária, Pereira (2006) afirma que

também o pesquisador é alvo da sua pesquisa, posto que sabe-se um sujeito que não está a espreitar uma realidade que lhe é estranha, mas atua como um sujeito dotado de valores, que tem consciência de que a sua presença não representa apenas uma interferência, mas é fundadora de um tipo de discursividade só possível pela sua presença.

Ao partir dessa perspectiva para pensar a produção do conhecimento com auxílio da abordagem da etnografia virtual ${ }^{1}$ (ou netnografia), é possível afirmar que a

\footnotetext{
${ }^{1}$ Amaral (2009, p. 15) afirma que o "termo netnografia tem sido mais amplamente utilizado pelos pesquisadores da área do marketing e da administração, enquanto o termo etnografia virtual é mais utilizado pelos pesquisadores da área da antropologia e das ciências sociais". O objetivo deste artigo não é o de discutir as especificidades dos termos mencionados, por isso, eles são utilizados aqui como sinônimos.
} 
interação nas redes sociais com jovens internautas se faz de forma participativa, levando em consideração o modo pelo qual são compartilhados gostos, objetivos, crenças e ideias, produzindo sentidos diversos pela necessidade dos jovens de se relacionarem com o conhecimento e a cultura a partir de processos comunicacionais mediados pelas diversas interfaces digitais.

Jobim e Souza e Kramer (2003, p. 15) criticam a ideia de que docentes e discentes são considerados, '‘aqueles que ensinam' e 'aqueles que aprendem'. Eles são sujeitos históricos. São produtores de linguagem. Linguagem que os constitui como sujeitos humanos e sociais sempre imersos em uma coletividade".

Ao adotar na investigação a perspectiva de trabalhar com os sujeitos - e não sobre os sujeitos -, a ideia de que o pesquisador é o detentor das respostas a serem descobertas é rompida, e o próprio jovem passa a se constituir como coautor na construção coletiva do conhecimento, num processo de investigação que se constrói gradualmente com o outro, possibilitando que todos se afetem e se deixem afetar na troca.

Em uma pesquisa realizada com sujeitos integrantes da cultura "electroindustrial", Amaral (2009) se apropria da netnografia como uma abordagem que vem permitindo reconhecer a alteridade e a coautoria, ressaltando principalmente a ideia de que o conhecimento é construído em comunhão com o pesquisador. Para a autora, as interações online "potencializam ainda mais os níveis de proximidade e a disseminação dos dados da pesquisa, além da possibilidade de alterações e correções de detalhes que, à primeira vista, também possam não ter ficado claros ao pesquisador" (p. 19).

A etnografia virtual auxilia o pesquisador, segundo Rocha e Montardo (2005, p. 10), a ser "testemunha de um mundo que também se desenrola no ciberespaço". E é pela potencialidade de auxiliar os pesquisadores a capturar as marcas do cotidiano online de jovens usuários das redes sociais que essa abordagem metodológica vem tendo "espaço assegurado nas pesquisas onde os objetivos incluem saber 'o que as pessoas estão realmente fazendo com a tecnologia'" (GUTIERREZ, 2009, p. 10).

Esse foi o motivo que levou, nesta pesquisa, à escolha da etnografia virtual como procedimento para operar com a especificidade do objeto de estudo, tendo em vista sua propriedade em se debruçar sobre "os processos de sociabilidade e os 
fenômenos comunicacionais que envolvem as representações do homem dentro de comunidades virtuais" (AMARAL; NATAL; VIANA, 2008, p. 35).

Assim, foi objetivo deste estudo buscar, com os sujeitos, conhecer fatos cotidianos nas redes sociais do Facebook, potencializando a relação construída no campo a partir das conversas online, tanto individuais quanto coletivas, com jovens usuários dessa interface.

A etnografia virtual aponta que é possível conviver com os sujeitos em um novo lócus de pesquisa, o ciberespaço. Este lócus se constituiu, neste caso, como um ambiente propício para legitimar e reconhecer o outro como legítimo outro na produção de conhecimentos que vem sendo, mais recentemente, exercida cotidianamente também pelos sujeitos nas redes sociais da internet.

A escolha do Facebook como campo empírico possibilitou criar vínculos sociais com os jovens no ciberespaço, que "já fez da cultura um lugar de produção de conteúdo, de conexão livre entre pessoas e grupos e de reconfiguração da vida social, política e cultural" (LEMOS, 2010, p. 29).

Lemos e Lévy (2010, p. 53) também discutem que o ciberespaço hoje apresenta maior liberdade de uso aos usuários, propiciando a comunicação em escala planetária pelas "possibilidades de escrita coletiva, de aprendizagem e de colaboração na e em rede. Exemplos estão em expansão hoje, como comprovam a popularidade de redes sociais como Facebook".

\section{APRENDENDO E ENSINANDO COM O OUTRO NO CIBERESPAÇO ${ }^{2}$}

Segundo dados do Ipobe/NetRatings (LEMOS, 2010), o Brasil apresenta cerca de 45 milhões de internautas, sendo que mais da metade destes acessa a internet da própria residência. Essa quantidade exponencial de internautas brasileiros fica evidente na popularidade de softwares sociais como o Facebook, interface que vem interconectando um número considerável de usuários nos processos comunicacionais da cibercultura em sua fase atual.

\footnotetext{
${ }^{2}$ Para realizar as análises das conversas online, foram usadas siglas na identificação dos jovens, preservando, desta forma, a identidade dos participantes da pesquisa.
} 
É visível a participação de jovens em dinâmicas de colaboração envolvendo o consumo e a produção intensa de arquivos nos mais diversos formatos multimídias, criando formas distintas de interagir com o outro a partir dos artefatos tecnológicos.

Uma conversa estabelecida entre um grupo de jovens das Ciências Biológicas da UFRJ se inicia quando $\boldsymbol{A P}$, de 22 anos, comenta o link de um vídeo compartilhado por EB no Facebook. O vídeo do Youtube "Rio 3D Filme: trailer legendado Brasil HD”3 é um trecho do filme Rio, animação dirigida pelo brasileiro Carlos Saldanha, e mostra parte da trama que acontece com os personagens na Cidade Maravilhosa, cenário reconstruído digitalmente e que é bastante fiel à cidade do Rio de Janeiro, retratando algumas das praias da Zona Sul, bem como a Pedra da Gávea e o Cristo Redentor.

O foco das discussões girou em torno, principalmente, do reconhecimento e identificação dos personagens com as diferentes espécies de aves que aparecem no filme, e apontou para um debate colaborativo na e em rede bastante específico do campo das Ciências Biológicas, até pelo uso de nomes científicos comumente utilizados pelos especialistas que estudam os pássaros:

$A Q:$ Fazia tempo que não ria tanto com um filme ;)

EB: duas:)

PG: três!... e já estou com ele em casa para passar pros meus alunos!... ahuahau professor de primeira mão!

(...)

MP: Esse é pros Arólogos... vcs notaram tds os Philodendrons q aparecem no filme?! Eles estavam por toda a mata... XD achei o máximo!

EB: tinha um o tempo todo que parecia o undulatum. Tinha uma nervação esquisita, mas $n$ faz diferença pra quem não conhece e era muito bonito $: D$

EB: já viu alguma representação de floresta tropical que preste sem Araceae, MP? :p

MP: é verdade... mas senti falta das minhas Commelinaceae e das minhas Orchidaceae! Mas eu tbm achei q aquele Philo parecia MT um undulatum com defeito. $=D$

LC: Adorei seu comentário EB!!! Floresta tropical sem Araceae não é floresta!!!!!

LC: Aquele lá certamente não é o undulatum, é um outro de folhona que eu vejo por aí mas não sei quem é, mas Philo Philo, não Meconostigma. As matas fechadas do Rio não tem undulatum (e se tivessem, ele seria mais alto).

EB: LC, até parece que ele ta muito bem representado no desenho suficientemente pra identificar né : $P$ eu sei de qual tu ta falando, mas tb não tá igual a ele. Desenharam inclusive ele praticamente aleijado, sem caule. Enfim, por isso diz-se: algo parecido com o P. undulatum :)

LC: $A h, \quad E B . . . \quad$ Não era o undulatum... Era o paludicola!!!!1 HUHauhauahauahauh!!!!!

${ }^{3}$ O vídeo encontra-se disponível em: <http://www.youtube.com/watch?v=LqkwNUiFqLs. $>$. Acesso em: 01 jun. 2011. 
AP: Gente, esverdiei com essa conversa...

Pesquisador: e eu boiei rsrs mas curti do mesmo jeito! =)

(...)

LC: Falei que tinha virado assunto interno... Hauhauahauahauh!!!!!

Na concepção de Amaral, Natal e Viana (2008), a netnografia é "um dos métodos qualitativos que amplia o leque epistemológico dos estudos em comunicação e cibercultura" (p. 35), embora não se trate da mera transposição do método etnográfico para a realização da pesquisa no ciberespaço. A própria distância física entre os sujeitos nas investigações netnográficas supõe repensar a abordagem a ser utilizada pelo pesquisador. Até porque, segundo mostra Gutierrez (2009, p. 11), "Diferentemente da etnografia tradicional, a netnografia não exige a presença física do pesquisador". Entretanto, a autora coloca que "se não houver interação, o pesquisador poderá passar despercebido, por exemplo" (p. 11).

Embora o antropólogo Carlos Rodrigues Brandão (2003) não esteja referindose às pesquisas realizadas no ciberespaço, ainda assim levanta um aspecto do estudo de campo que permite refletir sobre a importância da interlocução entre pesquisador e pesquisados, ao comentar o quanto é mais significativo "quando [os sujeitos] podem dizer de maneira mais livre e dialógica a alguém que os ouve o que pensam e sentem, em vez de responderem a perguntas ao estilo 'sim' ou 'não'” ( $p$. 43-44).

Jobim e Souza (2007), acerca das pesquisas que fazem uso de entrevistas, também mostra que, quando se estabelece um diálogo no campo, a troca de experiências pessoais é imprescindível para contribuir com a produção de conhecimento, que deve ser compartilhado para ser construído. Morin (1999, p. 27) também me auxilia a entender que "a informação nasce do nosso diálogo com o mundo, e nele sempre surgem acontecimentos que a teoria não tinha previsto".

Sgarbi (2010, p. 1) faz uma crítica "à noção de autoridade ligada ao conhecimento", que poderia ser exemplificada quando um palestrante, "especializado" em relação a um determinado saber, impõe-se ao público, ou quando um pesquisador concebe-se "soberano" em relação aos sujeitos na sua investigação científica.

Em uma perspectiva que percebe a pesquisa como um encontro de alteridades, as relações entre o pesquisador e os jovens usuários do Facebook foram estabelecidas no sentido de conceber a todos como parceiros da tarefa de 
conhecer o que ainda é desconhecido. Entendendo com Morin (1999, p. 30) que "o conhecimento navega em um mar de incerteza", os sujeitos da presente investigação foram reconhecidos como coautores do estudo. Cabe dizer que o próprio objeto de pesquisa, ainda não suficientemente explorado pelo campo da educação, supõe essa postura do pesquisador de se colocar diante do pesquisado como se estivesse "navegando num mar de incertezas".

Pesquisador: "Nossa, vivendo e aprendendo com as pessoas aqui no Facebook! :) Ah, e vocês costumam aprender muito por aqui?".

Pesquisador: "Huh? Explica please!".

Pesquisador: "Mas CS, de que tipo de conhecimento você está falando?".

RL: "Ai!!! Você está lançando a semente da dúvida!! Ou será que é da discórdia?! kkk"

As perguntas acima mencionadas foram levantadas no decorrer de diversas conversas individuais e coletivas no Facebook e apontam para o importante papel do diálogo, inclusive entre pesquisador e sujeitos, na produção coletiva do conhecimento em rede.

Todos estão implicados e têm a possibilidade de produzir sentidos nas conversas online, em um cenário de colaboração onde a interação entre os pares promove reflexões que propiciam a todos serem protagonistas ativos que questionam e indagam inspirados pela vontade e pela curiosidade de aprender com o outro.

Sobre a importância do diálogo na experiência de ensinar-aprender, Brandão (2003, p. 70, grifos meus) argumenta que

[...] quando se ensina o que ainda não se sabe, se pergunta. Quando se pergunta, de alguma maneira o ato seguinte é uma forma ou experiência de pesquisa. É um levar aos outros em diálogo comigo as minhas perguntas em busca das deles e, se possível, de respostas que eles se deram e, agora, dão a mim; perguntas que faço a mim mesmo.

Essa foi a experiência que se delineou na interação estabelecida com os sujeitos nas interfaces digitais. O próprio aplicativo $S k y p e^{4}$ também possibilitou entrar em contato com alguns usuários do Facebook para que ajudassem na tarefa

\footnotetext{
${ }^{4}$ Para mais informações e download desse aplicativo - que realiza ligações, chamadas com vídeo e apresenta também chat - ver <http://www.skype.com. . . Acesso em: 15 mar. 2011.
} 
de melhor entender, esclarecer e ampliar algumas das discussões tecidas com/entre os sujeitos no referido software social.

Para que fosse possível relatar a experiência da conversa entre os biólogos da UFRJ sobre o vídeo do Youtube, anteriormente mencionada, houve a participação do jovem $\boldsymbol{A P}$, que conhece bem a geografia da cidade do Rio de Janeiro, e que participou na descrição do trecho de dois minutos do filme Rio, apontando justamente que, no presente estudo, os sujeitos são ativos na produção do conhecimento:

Pesquisador: ah, quando tiver um tempinho...

Pesquisador: aquela praia que aparece no video http://www.youtube.com/watch?v=LqkwNUiFqLs. Qual é a praia? é a de Copacabana? nao sei se é possível termos certeza...

AP: acho q sim.

AP: na verdade eles [os personagens] saem do Leblon, da pedra da gavea

AP: vao até o litoral do leblon

Pesquisador: obrigado! vou colocar então: "uma praia da Zona Sul", que era a minha intenção inicial rsrs

AP: nao

AP: é ipanema

Pesquisador: Zona Sul rsrs

Reconhecendo a importância dos sujeitos como coautores do presente estudo, foi imprescindível a escolha de um campo que aproximasse pesquisador e os jovens usuários, buscando posturas que primam não por "verdades absolutas", mas por perguntas que, constantemente, foram sendo formuladas a partir da relação estabelecida no campo com os sujeitos.

De acordo com a abordagem teórico-metodológica adotada, pesquisar com jovens nas redes sociais digitais implica estabelecer diálogo respeitoso, em que o pesquisador não ocupa o espaço de alguém que busca "levar o conhecimento" àqueles que supostamente nada saberiam, mas de alguém que, assim como mostra Amaral (2009, p. 15), apresenta "mais questionamentos e dúvidas do que respostas prontas".

Dúvidas técnicas sobre o $3 G^{5}$ também surgiram e reforçam o importante papel dos sujeitos como parceiros da investigação, auxiliando na melhor

\footnotetext{
${ }^{5}$ As "redes $3 G$ permitem telefonia móvel de longo alcance e evoluíram para incorporar redes de acesso à Internet em alta velocidade e Vídeo-telefonia". Informação disponível em: <http://pt.wikipedia.org/wiki/3G.. . Acesso em: 25 fev. 2012.
} 
compreensão sobre as diferentes velocidades de acesso à internet via dispositivo móvel:

\begin{abstract}
Pesquisador: Oi DV, eu queria perguntar sobre internet 3G! Ela é boa? Estive vendo na [...] e o plano mais barato está 29,90 (mas achei estranha a velocidade: 32kbps... não sei se isso é rápido ou devagar para 3G).. abraço! DV: Olha, o 3G é bem variável... Com um sinal bom, funciona bem, mas tem se o sinal estiver ruim........ >.<" 32kbps eu acho que é pouco sim... Eu já usei a minha até para jogar no LOTRO [The Lord of The Rings Online], então com certeza é mais rápida... Só tenha em mente uma coisa: $3 G$ é pra uso no dia-a-dia, não para downloads... Pra isso ela é um lixo. XD Abraço!

Pesquisador: valeu pelas dicas, DV! Eu estava pensando nisso mesmo... mas soh uma ultima perguntinha: eu gosto muito de ver videos de musica no youtube (inclusive aprecio também aqueles que tem a opção $720 p$ e 1080p)... será que, com essa velocidade, tem como eu ver tranquilamente vídeos no youtube? não precisa, necessariamente, estar com essas resolucoes...

DV: A $3 G$ normal consegue... A 32 Kbps deve ficar lento, mas não é impossível... Adianto que vai demorar razoavelmente pra carregar, cara... =/ E com resolução alta, você vai levar BEM mais tempo pra ver... Dá uma checada, vê se não tem outra $3 G$ mais rápida que vc tenha condição de pagar... Pode valer a pena! lo
\end{abstract}

Pesquisador: obrigado, DV! vou ter que ver outras operadoras mesmo...

Dialogar na rede com os sujeitos da pesquisa supõe estar conhecendo as diferentes possibilidades de usos da internet móvel, pois permite estar ainda mais próximo dos sujeitos na mobilidade. A conversa ressalta este sentido, pois proporcionou novas informações sobre o $3 G$ a partir da interação com o internauta $D V$, de 21 anos.

Canclini (2005, p. 17) auxilia a refletir sobre o papel dos sujeitos da investigação como coautores, quando diz que a pesquisa "remete à confrontação e ao entrelaçamento, àquilo que sucede quando os grupos entram em relações e trocas", o que implica a compreensão de que "os diferentes são o que são, em relações de negociação, conflito e empréstimos recíprocos" (p. 17).

O papel do pesquisador enquanto usuário que pesquisa com outros usuários no Facebook é, assim, o de buscar questionar, compreender o cotidiano da própria rede social da internet, levantando questionamentos no ciberespaço dentro de uma imersão que se faz partindo dos pressupostos metodológicos da etnografia virtual. Adotar as conversas online como procedimento metodológico também mostra que "a verdade não se encontra no interior de uma única pessoa, mas está na interação dialógica entre pessoas que a procuram coletivamente" (JOBIM E SOUZA, 2007, p. 92). 
Conforme Maturana (2002, p. 27), "a linguagem como fenômeno, como um operar do observador, não ocorre na cabeça nem consiste num conjunto de regras, mas ocorre no espaço de relações". Essa postura de compreender a importância do diálogo na pesquisa etnográfica virtual ocorreu, nesta pesquisa, em um espaço de convivência com o outro, onde pesquisador e sujeitos se transformaram mutuamente, como é o próprio ato de educar na perspectiva de ensejar a prática pela legitimidade dos sujeitos a partir do respeito mútuo na relação entre os pares.

"O educar se constitui no processo em que a criança ou o adulto convive com o outro e, ao conviver com o outro, se transforma espontaneamente, de maneira que seu modo de viver se faz progressivamente mais congruente com o do outro" (MATURANA, 2002, p. 29).

Neste contexto, a nova postura assumida na investigação é a de alguém que reconhece e legitima os diversos pontos de vista dos sujeitos, sem que os envolvidos na pesquisa abdiquem de suas respectivas identidades, subjetividades e contextos sociais aos quais pertencem. A partir daí, entende-se que o pesquisador, nas redes sociais da internet, precisa adotar uma perspectiva que constitui os sujeitos parceiros na tarefa de produzir coletivamente saberes sobre o objeto de estudo.

Ainda que não exista uma única forma de se fazer etnografia virtual (ROCHA; MONTARDO, 2005), a conversa online que se estabeleceu com os participantes da pesquisa mostrou a diluição das fronteiras entre o real e o virtual, reforçando a ideia de indissociabilidade entre elas. Isto porque, segundo mostra Gutierrez (2009), as redes sociais da internet constituem-se enquanto parte do território físico, onde a geografia do ciberespaço, embora não coincida "com a das redes comunicacionais que se desenham no território físico, [...] nem por isso constitui uma dimensão estanque da realidade. Ao contrário, as redes se interpenetram e dialeticamente se constroem e reconstroem" (p. 1).

Indo nessa mesma direção, Rocha e Montardo (2005) defendem que a rede mundial de computadores adquiriu centralidade nas práticas culturais cotidianas de muitos sujeitos pela diluição das fronteiras do real e do virtual.

Para Gutierrez (2009, p. 1), a cultura digital "se constrói na emergência das ações, reações, sociabilidades, hegemonias, movimentos que derivam das marcas que a tecnologia deixa na sociedade contemporânea", tornando-se cada vez mais 
difícil pensar o ciberespaço e a cidade como espaços distintos que possam ser dicotomizados.

Diante disso, compreender os inúmeros aspectos que envolvem a relação estabelecida pelos usuários com a cultura digital é um desafio também para se pensar as redes sociais da internet na formação de professores.

\section{POSSIBILIDADES PARA SE PENSAR EDUCAÇÕES NA/COM A CIBERCULTURA: ALGUMAS PALAVRAS FINAIS}

Brandão (2003, p. 47, grifos do autor), referindo-se à pesquisa como produção que supõe o reconhecimento de pesquisador e pesquisados como coparticipantes da construção de conhecimento, diz o seguinte: "me vi envolvido de corpo e alma com uma experiência de criação de novos saberes em que o 'outro', sujeito de minha investigação científica, passa a ser também um praticante direto de nossa pesquisa".

Essa concepção de pesquisa permite ao pesquisador afetar $o$ outro e, ao mesmo tempo, se deixar afetar pelo outro, numa relação de cumplicidade e pertencimento construída entre/com jovens que habitam as redes sociais da internet.

E sob a perspectiva da alteridade, essa pesquisa se desenvolveu com outros jovens no ciberespaço legitimando o Facebook como um lugar de autoria, com a participação de todos em processos de ensino-aprendizagem que apresentaram muitos movimentos de troca de arquivos. Ou seja, essa é uma perspectiva "de troca entre amigos, entre parceiros, possibilitando a dinâmica de produção colaborativa com uma intensificação da produção de conhecimentos e culturas" (PRETTO, 2010, p. 7).

A parceria criada baseou-se na ideia de que, juntos, pesquisador e pesquisados produzem colaborativamente os conhecimentos, segundo Lemos e Lévy (2010, p. 83). De acordo com estes autores, com a possibilidade de "nos organizar, conectar e produzir coisas coletivamente (o princípio de conexão), iremos, com certeza, produzir reconfigurações nas instituições culturais, no fazer político, no espaço público, na democracia".

Diante do exposto, a abordagem teórico-metodológica adotada para investigar com outros jovens no Facebook trouxe oportunidade de aproximar pesquisador e 
sujeitos, buscando o diálogo via computador que estivesse comprometido em conhecer cada vez mais e melhor os sentidos construídos por todos na relação com o mundo da cultura e do entretenimento.

Pesquisar com outros jovens no ciberespaço é promover a ideia de que os pontos de vista são reconhecidos e legitimados e as "vozes são livres" para conhecer e se deixar conhecer por tantos outros jovens internautas nas redes sociais.

É interessante considerar o Facebook nos processos de ensinar e aprender, assim como pensar a educação na/com a cibercultura. Mais do que ser utilizado como uma ferramenta na promoção de um ambiente institucionalizado do saber e de se constituir meramente como uma espécie de sala de aula virtual, o Facebook se revela importante como um software social que agrega dinâmicas comunicacionais e proporciona aos professores e seus estudantes outras formas de tecer "teias complexas de relacionamento com o mundo" (SANTOS, 2002, p. 121).

Orofino $(2005$, p. 46$)$ alerta para o fato de que se torna preciso conhecer "o universo cibernético por onde as mentes criativas de nossos filhos e alunos navegam horas a fio nos confins do mundo digitalizado do computador, da internet". Não há dúvida de que os jovens encontram-se motivados pelas conversas tecidas entre si, que se constituem como uma linguagem dinâmica própria da cibercultura, com a presença marcante da linguagem áudio-visual.

Sendo assim, de que forma a educação poderia incorporar essas novas linguagens na prática pedagógica, com o objetivo de ampliar os processos de ensino-aprendizagem para além dos limites físicos da sala de aula?

Pensar a educação na/com a cibercultura é mais do que a mera implementação das mídias digitais na sala de aula; é reconhecer e legitimar outras formas de aprender; um aprender que seja praticado nas dinâmicas do compartilhamento, da colaboração na/em rede com outros internautas.

Conforme Santos (2002, p. 119), "não basta apenas inovar a forma nem o conteúdo dos materiais ou estratégias de ensino. É necessário transformar o processo de comunicação dos sujeitos envolvidos". Isso não significa desvalorizar ou inutilizar determinados suportes que ainda são bastante utilizados nas práticas pedagógicas, como o quadro-negro, o livro didático, o retroprojetor, dentre outros, mas promover novas formas de entrar em contato com os conhecimentos. 
Nóvoa (1999, p. 16) também ressalta que "é fundamental encontrar espaços de debates, de planificação e de análise, que acentuem a troca e a colaboração entre os professores", e o ciberespaço poderia se constituir como um ambiente privilegiado para isso.

Pensar a educação na/com a cibercultura não se trata de planejar práticas educativas no Facebook, mas de se apropriar desta interface para ampliar os canais comunicativos entre estudantes e seus professores. Nesta perspectiva, as redes sociais da Internet poderiam propiciar que as diferentes vozes dos estudantes sejam ouvidas e interpeladas, criando vínculos mais estreitos entre todos os envolvidos nos processos de ensinar e aprender. Dessa forma os limites físicos das salas de aula poderão ser rompidos, garantindo que professores e estudantes encontrem espaços de troca nas interfaces digitais.

E, por fim, refletir sobre o uso do Facebook na formação de professores também remete à compreensão de estratégias por meio das quais a educação poderia se apropriar do fenômeno da cibercultura. E, assim, construir com a juventude novas estratégias em sala de aula, abarcando manifestações culturais decorrentes de informações que circulam livremente nas/pelas redes sociais da Internet.

\section{DILTON RIBEIRO COUTO JUNIOR}

Mestre em Educação pelo Programa de Pós-Graduação em Educação da Universidade Estadual do Rio de Janeiro (UERJ). Doutorando do PPGE da UERJ e tutor à distância do CEDERJ, no curso de Pedagogia da UERJ.

\section{REFERÊNCIAS}

AMARAL, Adriana. Autonetnografia e inserção online: o papel do pesquisadorinsider nas práticas comunicacionais das subculturas da Web. Revista Fronteiras estudos midiáticos. v. 11, n. 1, p. 14-24, jan./abr., 2009. Disponível em: $<$ www.fronteiras.unisinos.br/pdf/62.pdf. $>$. Acesso em: 22 jan. 2012.

; NATAL, Geórgia; VIANA, Lucina. Netnografia como aporte metodológico da pesquisa em comunicação digital. Revista FAMECOS, n. 20, p. 34-40, 2008. Disponível em: $<$ http://revistaseletronicas.pucrs.br/ojs/index.php/famecos/article/viewFile/4829/3687 >. Acesso em: 15 nov. 2011. 
BRANDÃO, Carlos Rodrigues. A pergunta a várias mãos: a experiência da partilha através da pesquisa na educação. São Paulo: Cortez, 2003.

CANCLINI, Néstor García. Diferentes, desiguais e desconectados: mapas da interculturalidade. Rio de Janeiro: UFRJ, 2005.

GUTIERREZ, Suzana de Souza. A Etnografia virtual na pesquisa de abordagem dialética em redes sociais on-line. In: REUNIÃO ANUAL DA ASSOCIAÇÃO NACIONAL DE PÓS-GRADUAÇÃO E PESQUISA EM EDUCAÇÃO, 32a , 2009, Caxambu. Anais... Caxambu: Espaço Livre, 2009, p. 1-16. Disponível em: <http://www.anped.org.br/reunioes/32ra/arquivos/trabalhos/GT16-5768--Int.pdf. $>$.

Acesso em: maio 2011.

JOBIM E SOUZA, Solange. Dialogismo e alteridade na utilização da imagem técnica em pesquisa acadêmica: questões éticas e metodológicas. In: FREITAS, Maria Teresa; JOBIM e SOUZA, Solange; KRAMER, Sonia (Org.). Ciências humanas e pesquisa: leituras de Mikhail Bakhtin. 2. ed. São Paulo: Cortez, 2007. p. 77-94.

; KRAMER, Sonia. Experiência humana, história de vida e pesquisa: um estudo da narrativa, leitura e escrita dos professores. In: KRAMER, Sonia; JOBIM E SOUZA, Solange (Org.). História de professores: leitura, escrita e pesquisa em educação. São Paulo: Ática, 2003. p. 13-42.

LEMOS, André. Os sentidos da tecnologia: cibercultura e ciberdemocracia. In: ; LÉVY, Pierre. O futuro da internet: em direção a uma ciberdemocracia planetária. São Paulo: Paulus, 2010. p. 21-31.

; LÉVY, Pierre. O futuro da internet: em direção a uma ciberdemocracia planetária. São Paulo: Paulus, 2010.

LÉVY, Pierre. Prefácio à edição brasileira. A mutação inacabada da espera pública. In: LEMOS, André; LÉVY, Pierre. O futuro da internet: em direção a uma ciberdemocracia planetária. São Paulo: Paulus, 2010. p. 9-20.

MARINHO, Simão Pedro P. Novas tecnologias e velhos currículos; já é hora de sincronizar. Revista E-curriculum, São Paulo, v. 2, n. 3, p. 1-28, dez. 2006. Disponível em: <http://www.pucsp.com.br/ecurriculum. >. Acesso em: 23 dez. 2011.

MATURANA, Humberto. Emoções e linguagem na educação e na política. Tradução de José Fernando Campos Fortes. Belo Horizonte: UFMG, 2002.

MORIN, Edgar. Por uma reforma do pensamento. In: PENA-VEJA, Alfredo; ALMEIDA, Elimar Pinheiro de (Org.). O pensar complexo. Rio de Janeiro: Garamond, 1999. p. 21-34.

NÓVOA, António. Os professores na virada do milênio: do excesso dos discursos à pobreza das práticas. Educação e Pesquisa, São Paulo, v. 25, n. 1, jun. 1999. Disponível em: <http://www.scielo.br/scielo.php?script=sci arttext\&pid=S151797021999000100002\&lng=en\&nrm=iso. . . Acesso em: 23 jun. 2009. 
OROFINO, Maria Isabel. Mídias e mediação escolar: pedagogia dos meios, participação e visibilidade. São Paulo: Cortez, 2005.

PEREIRA, Rita Ribes. Infância, mídia e educação: perspectivas de pesquisa intervenção (as crianças e as telenovelas). Projeto de Pesquisa, UERJ/FAPERJ, 2006. Mímeo.

PRETTO, Nelson De Luca. Professores universitários em rede: um jeito hacker de ser. In: ENCONTRO NACIONAL DE DIDÁTICA E PRÁTICA DE ENSINO CONVERGÊNCIAS E TENSÕES NO CAMPO DA FORMAÇÃO E DO TRABALHO DOCENTE: POLÍTICAS E PRÁTICAS EDUCACIONAIS, 15 2010 , Belo Horizonte. Anais.... Belo Horizonte: UFMG, 2010, p. 1-15. Disponível em: <https://blog.ufba.br/nlpretto/files/2010/04/endipe pretto v1 1 com imagem enviad o08032010 webpretto atualizada.pdf. >. Acesso em: 20 mar. 2011.

ROCHA, Paula Jung; MONTARDO, Sandra Portella. Netnografia: incursões metodológicas na cibercultura. Revista da Associação Nacional dos Programas de Pós-Graduação em Comunicação (e-compós), p. 1-22, dez. 2005. Disponível em: $<$ http://www.compos.org.br/seer/index.php/e-compos/article/viewFile/55/55.>. Acesso em: abr. 2011.

SANTOS, Edméa Oliveira dos. Formação de professores e cibercultura: novas práticas curriculares na educação presencial e a distância. Revista da FAEEBA Educação e Contemporaneidade. Salvador, v. 11, n. 17, p. 113-122, jan./jun., 2002.

SGARBI, Paulo. Imagens e outras mídias nas reflexões de ensinoaprendizagens cotidianas de professores na tarefa de formação dos leitores em si mesmos. Palestra proferida no Encontro Nacional de Mídia e Formação de Leitores. set. 2010, $17 \mathrm{p}$.

\section{Websites visitados}

Facebook: http://www.facebook.com/

Skype: http://www.skype.com/

Wikipédia - A enciclopédia livre: http://pt.wikipedia.org/

YouTube: http://www.youtube.com/ 